\title{
Settling velocity and mass settling flux of flocculated estuarine sediments
}

\author{
R.L. Soulsby ${ }^{1}$, A.J. Manning ${ }^{1,2}$, J. Spearman $^{1}$ and \\ R.J.S. Whitehouse ${ }^{1}$ \\ ${ }^{1}$ HR Wallingford, Howbery Park, Wallingford, Oxon OX10 8BA, United Kingdom \\ School of Marine Science \& Engineering, University of Plymouth, Devon, PL4 8AA, United Kingdom
}

Published in the Journal of Marine Geology (2013), pp. 1-12

\section{Abstract}

New formulations are presented for the settling velocity and mass settling flux (the product of settling velocity and sediment concentration) of flocculated estuarine mud. Physics-based formulae for these are developed based on assumptions of a two-class floc population (microflocs and Macroflocs) in quasi-equilibrium with the flow. The settling velocities of microflocs and Macroflocs are related to floc size and density via the Kolmogorov microscale as a function of turbulent shear-stress and sediment concentration, including heightdependence and floc-density-dependence. Coefficients in the formulae are calibrated against an existing large data-set of in situ observations of floc size and settling velocity from Northern European estuaries. Various measures of performance show that the resulting formulae achieve an improved level of agreement with data compared with other published prediction methods. The new formulae, with the original calibration coefficients, perform well in tests against independent measurements made in two estuaries.

\section{Highlights:}

- Presents new formulae for settling velocity and mass settling flux of suspended mud

- Based on physics, calibrated against large field data-set

- Measures of performance versus data compare favourably with previous methods

- Integrated mass settling flux predicted to within $2 \%$

\section{Keywords}

cohesive sediment; settling velocity; mass settling flux; flocculation; suspended particulate matter; mud transport models

\section{Introduction}

\subsection{Background}

Many estuaries world-wide are dominated by muddy sediments. The presence, suspension and deposition of mud strongly influence the morphology of estuaries, and impact on both their natural characteristics and on man's use of them for transport, industry, commerce, recreation and fishing. Consequently, understanding the mud processes has been a subject of intensive research effort (e.g. Dyer, 1986; Dronkers and Van Leussen, 1988; Healy et al., 2002). 
A key aspect of mud dynamics is the settling process resulting in deposition of sediments. Specifying the settling velocity of muddy sediments is much more complex than that of sand, due to its dependence on the state of flocculation, which in turn depends on the concentration of sediment, the turbulence characteristics, properties of the water and sediment, and the time/space-history of all of these. Numerous methods of predicting such settling velocities have been proposed, and some of these will be summarised later.

The aim of the present study is to develop a generic physically-based model for the mass settling flux of natural estuarine cohesive sediments. This is achieved by taking as a starting point the empirical formulae for mud floc settling velocity and mass settling flux presented by Manning and Dyer (2007, hereafter MD07), and referred to as the 'Manning Floc Settling Velocity' (MFSV) model. The MFSV has been applied successfully in various estuarine modelling applications (e.g. Spearman et al., 2011).

Nevertheless the model has some perceived weaknesses: (a) the purely empirical curve-fitting approach used to obtain the MFSV model limits its potential applicability because it is only weakly based on physical principles and could possibly be site-specific; (b) it contains a large number of fitting coefficients, which could lead to unexpected behaviour outside the immediate range of calibration, (c) most of the coefficients are dimensional (i.e. the formulae are not dimensionally homogeneous) which indicates that other dimensional physical variables are missing; (d) outside the range of shear-stresses found in the data, the floc settling velocities are simply held constant at the values occurring at the limits of validity; (e) the settling velocity formulae were fitted piecewise within three bands of shear-stress values, but the three formulae have large concentration-dependent discontinuities at the boundaries between the bands. To overcome the last problem the MFSV algorithm employs interpolation between the curves, but the interpolation method is not well-justified and results are sensitive to the exact method used.

Because of these deficiencies, an improved method was sought, using the same large data-set and employing the same broad interpretation of the dependence of settling velocity on the independent variables of suspended particulate matter (SPM) concentration and turbulence intensity or shear-stress, but with a sounder basis in physics. The resulting physics-based formulae have broader applicability, are dimensionally homogeneous, have fewer (mainly nondimensional) coefficients, are continuous with respect to both SPM and turbulence intensity (shear-stress), and are extendible beyond the calibrated range in a more justifiable fashion.

Like the MFSV model, the main goal is to achieve a simple yet accurate mathematical description of the vertical mass settling flux (MSF), which becomes the depositional flux close to slack water. This flux is the product of the SPM concentration and the settling velocity of the suspension. The target is to achieve at least a similar level of agreement with data to that obtained by the MD07 formulae, while reducing the level of empiricism. The new method draws on the interpretations of the data made in the development of the MFSV model by MD07, and also has commonalities with (but also differences from) the method of Winterwerp et al. (2006) in terms of the physics employed.

The MD07 data-set includes 157 field measurements of the settling velocity and size of mud flocs taken in situ between 1996 and 1999 using the INSSEV instrument (Fennessy et al., 1994) in the estuaries of the Tamar (UK), Gironde (France) and Dollard (The Netherlands). We have further tested the new method against independent INSSEV data measured in the Tamar in 2003 and the Scheldt (Belgium) in 2005.

The formulation presented by MD07 made use of the hierarchical division of flocs into microflocs and Macroflocs (e.g. Krone, 1963; Eisma, 1986), elaborated on in Section 3. Note that, because of the similarity in spelling of microflocs and Macroflocs, a capital M will be used for Macroflocs to highlight the distinction. Quantities associated with microflocs and Macroflocs are identified by subscripts $\mu$ and $M$ respectively. 


\subsection{Existing models of floc settling}

Many theoretical treatments of particle aggregation build on the approach developed in a pioneering paper by Smoluchowski (1917), in which the aggregates are divided into a number of size classes. His general approach is summarised by Elimelich et al. (1995), and is encapsulated in a differential equation in which the growth rate of the number of aggregates in a given class is related to the gain of new members, and loss of existing members, due to collisions between aggregates in different classes. Four mechanisms giving rise to collisions have been identified (e.g. Dyer, 1986; Krishnappan, 1991; Elimelich et al, 1995; Verney et al, 2010), namely Brownian motion, fluid shear, inertial collision, and differential settling. Expressions for the collision rates of all these mechanisms have been deduced in terms of the sizes of the two classes of aggregate involved in the collision. Expressions have also been proposed for the shear-induced break-up of flocs (e.g. Winterwerp, 1999; Verney et al, 2010), although these are less well-established than those for aggregation. Krishnappan (1991) included all four aggregation mechanisms (but no break-up mechanism) in a model of floc formation and settling in rivers, whereas Winterwerp (1999) and Verney et al. (2010) concluded that the most important processes were shear-induced aggregation and shear-induced break-up. Thus low rates of shear increase the size of flocs, high rates of shear reduce the size of flocs, and, for a given shear rate and SPM concentration, an equilibrium distribution of floc sizes will develop after a sufficiently long time. Winterwerp (1999) and Verney et al. (2010) developed fully time-evolving, multifraction models of floc formation and break-up, which describe the physico-chemical processes in great detail, but in both approaches a number of site-dependent parameters need to be given values, and the models are relatively heavy on computational time.

In practical applications concerning the erosion, transport and deposition of mud in estuaries, various methods of specifying the settling velocity $\left(w_{s}\right)$ of the mud flocs have been used. These methods involve different combinations of input variables, and different numbers of coefficients (some of which are sitespecific) to be specified. They are listed in order of increasing complexity below.

1. Specify a fixed value of $w_{\mathrm{s}}$, usually in the range $0.5-5 \mathrm{~mm} \cdot \mathrm{s}^{-1}$, sometimes used as a tuning parameter to match predicted erosion and deposition patterns to observations for the undisturbed estuary. One coefficient.

2. Relate $w_{s}$ to the instantaneous SPM concentration through a power law (e.g. Whitehouse et al., 2000). Two coefficients.

3. Relate $w_{\mathrm{s}}$ to the instantaneous SPM concentration through a power law, including hindered settling (e.g. Whitehouse et al., 2000). Three coefficients.

4. Relate $w_{\mathrm{s}}$ to a turbulent shear parameter and a reference settling velocity (Van Leussen, 1994), usually linked to methods 2 or 3 . Three to five coefficients.

5. Relate $w_{\mathrm{s}}$ to a turbulent shear parameter and the instantaneous concentration (MD07). 27 empirically fitted coefficients.

6. Relate $w_{\mathrm{s}}$ to a turbulent shear parameter, instantaneous concentration, and water depth (Winterwerp et al., 2006). Seven coefficients.

7. Solve a differential equation to deduce the time-varying representative floc diameter, from which floc density is derived by fractal considerations, and $w_{\mathrm{s}}$ obtained from a Stokes-like formula (Winterwerp, 1999). Six coefficients.

8. Apply a time-evolving two-class population balance equation to determine the spatially and temporally changing distribution of fixed-size microflocs and size-varying Macroflocs for bimodal floc distributions, 
with a fractal relationship between floc size and mass to derive the distribution of settling velocities (Lee et al., 2011). 17 coefficients.

9. Apply a time-evolving, multi-fraction, model to determine the spatially and temporally changing distribution of the numbers of flocs in each size fraction, with a fractal relationship between floc size and mass to derive the distribution of settling velocities (Verney et al., 2010). At least seven coefficients.

The first six of these methods are relatively quick and easy to apply in practical models of estuarine mud distributions, whereas the last three are much less straightforward, and more computationally demanding. For the present purpose, it was decided that the fifth option, as used by MD07, gives a good compromise between representation of physico-chemical processes and computational simplicity, and a similar level of sophistication was adopted here. This decision was influenced by the good results obtained from modelling studies incorporating the MD07 method (e.g. Baugh and Manning, 2007; Spearman et al., 2011).

Approaches such as 4, 6 and 9 above use the shear parameter $G$ [units of $\mathrm{s}^{-1}$ ], which is the root-meansquare of the gradient in the turbulent velocity fluctuations, and MD07 (approach 5) use the turbulent shear stress $\tau$. These are related (see Section 3.2) through the shear velocity $u_{*}$ by $G=\left[u_{*}^{3} \xi / k v z\right]^{1 / 2}$, where $\mathrm{k}$ is von Karman's constant (taken as 0.40), $v$ is kinematic viscosity of the water, $z$ is height above the bed, $h$ is water depth, and $\xi=1-z / h$. Near the bed $(z<<h)$, this reduces to the commonly-used approximation $G=\left[u_{*}^{3} / \mathrm{kvz}\right]^{1 / 2}$, and $\tau \approx \tau_{0}=\rho u_{*}{ }^{2}$, where $\tau$ is shear-stress at height $z, \tau_{0}$ is bed shear-stress, and $\rho$ is density of water.

We adopt the two-class approach made up of small, dense microflocs and large, sparse Macroflocs proposed by MD07. The micro/Macrofloc approach was elaborated in the population-balance equations of Lee et al. (2011), who modelled the aggregation and fragmentation processes in detail. However, they felt that further intensive investigation of the aggregation and breakage kinetics would be required before their model was generally applicable. The present study takes a simpler approach to the physics, calibrated against the large MD07 data-set, with the intention that the coefficients obtained will be applicable to a wide range of estuarine situations.

The paper summarises the methods reported by Soulsby and Manning (2012) where full details of the background and methodology of the study can be found. As it stands, the new method (designated SM12) does not include the effects of hindered settling and turbulence damping at high SPM concentrations (larger than about $8 \mathrm{~kg} \cdot \mathrm{m}^{-3}$, Whitehouse et al. 2000), because the INSSEV data are not suitable for testing hindering effects since they cover only concentrations up to $8 \mathrm{~kg} \cdot \mathrm{m}^{-3}$. However, existing techniques can be applied to the method to account for these effects, in a similar way to that used by Spearman et al. (2011) with the MD07 method.

\section{Regional setting}

The data utilised in this study was acquired by A.J.M. from a series of in situ experiments conducted in four Northern European estuaries (Manning, 2004; Manning et al., 2011). The majority of the floc sampling was conducted in the predominantly mesotidal Tamar estuary (UK) during neap and spring tidal conditions (Dyer et al., 2002) in the upper reaches of the estuary (approximately $30 \mathrm{~km}$ from the mouth). Tamar data collection was within the tidal trajectory of the turbidity maximum, where a concentrated benthic suspension layer often formed in the near-bed region, causing SPM concentrations to reach $8 \mathrm{~kg} \cdot \mathrm{m}^{-3}$. Tamar turbulent shear stresses $(\tau)$ ranged from 0.04-0.7 N. $\mathrm{m}^{-2}$.

Further data were obtained during neap tides in the lower reaches of the Gironde estuary (south-west France), which is macrotidal and predominantly well mixed (Manning et al., 2004). SPM concentrations did 
not exceed $0.6 \mathrm{~kg} \cdot \mathrm{m}^{-3}$, but $\tau$ reached $1.9 \mathrm{~N} \cdot \mathrm{m}^{-2}$. The mesotidal Dollard estuary, a well mixed embayment in the Netherlands, provided the third data location (Dyer et al., 2000). Here the instrumentation was deployed on intertidal mudflats during neap tides, where the high water depth was $1.5 \mathrm{~m}$ and SPM and $\tau$ values were similar to those experienced in the Tamar Estuary during neap tides, but individual water depths were not measured. Independent data which we use for testing the pre-calibrated formulae were obtained during neap tides in the Scheldt estuary (Belgium) in the vicinity of Antwerpen (Manning et al., 2007). Throughout the passage of the turbidity maximum, SPM concentrations ranged between 0.15 and $0.3 \mathrm{~kg} \cdot \mathrm{m}^{-3}$, with $\tau$ restricted to a maximum of $0.24 \mathrm{~N} . \mathrm{m}^{-2}$. Outside the turbidity maximum zone $\tau$ rose to a peak of $1.47 \mathrm{~N} . \mathrm{m}^{-2}$, whilst the near-bed SPM concentrations rarely exceeded $0.1 \mathrm{~kg} \cdot \mathrm{m}^{-3}$.

During each data collection exercise, floc populations were sampled using the low intrusive, video-based INSSEV: IN-Situ SEttling Velocity instrument (Fennessy et al., 1994; Manning and Dyer, 2002). Individual floc sizes and settling velocities $\left(w_{s}\right)$ could be measured simultaneously. The INSSEV camera resolution can view flocs down to $20 \mu \mathrm{m}$ in size and as large as $4 \mathrm{~mm}$. Settling velocities generally ranging from $0.01 \mathrm{~mm}$. $\mathrm{s}^{-}$ ${ }^{1}$ to $35 \mathrm{~mm} . \mathrm{s}^{-1}$ can be measured by INSSEV. Similarly, INSSEV can operate within SPM concentrations of just a few $\mathrm{mg} . \mathrm{I}^{-1}$, with a practical upper operating limit of $8.5 \mathrm{~kg} \cdot \mathrm{m}^{-3}$. When comparing the majority of the calculated floc mass (from the INSSEV floc data) with the corresponding filtered concentration (from the water sample), the INSSEV SPM was typically within 85-90\% of the filtered SPM. Any unobserved fraction (sub-20 $\mu \mathrm{m}$ ) would be unflocculated particles with $w_{\mathrm{s}}<0.01 \mathrm{~mm} . \mathrm{s}^{-1}$ and therefore would have little effect on the MSF.

Theoretical considerations show that the distance $\left[\sim 10 s_{\mathrm{e}} w_{\mathrm{s}}^{2} /\left\{\left(s_{\mathrm{e}}-1\right) g\right\}\right.$, where $s_{\mathrm{e}}$ is the effective specific gravity of the floc and $g$ is acceleration due to gravity] through which a floc, starting from rest, achieves $99 \%$ of its terminal velocity is less than $1 \mathrm{~mm}$. This is very small compared with the distance of $\sim 150 \mathrm{~mm}$ between the release point and observation point in the INSSEV instrument, and therefore the settling velocities observed correspond closely to the terminal velocities of the flocs.

High frequency flow velocity and SPM concentration time-series data were recorded at $18 \mathrm{~Hz}$ using four twochannel $2 \mathrm{~cm}$ diameter discoidal electro-magnetic current meters and eight optical backscatter sensors, respectively, which were off-set laterally from the INSSEV sampling unit. Sampling deployments were conducted on a sub-tidal cycle time-scale at times when the flow conditions were either reasonably steady or gradually changing. The INSSEV unit was fixed at a height of $0.5 \mathrm{~m}$ to $0.65 \mathrm{~m}$ above the bed.

Each sample contained between about 40 individual flocs (for low SPM concentrations of 0.05-0.1 kg. $\mathrm{m}^{-3}$ ) and about 800 flocs (for high SPM concentrations of 4-6 $\mathrm{kg} \cdot \mathrm{m}^{-3}$ ). By measuring both the $x$-axis and $y$-axis of each observed floc, a spherically equivalent floc size $(d)$ could be determined from: $d=\left(d_{x} \cdot d_{\mathrm{y}}\right)^{0.5}$. Each floc population was then separated (based on floc size, as discussed later) into their Macrofloc $(d>160 \mu \mathrm{m})$ and microfloc $(d<160 \mu \mathrm{m})$ fractions (Eisma, 1986; Manning, 2004). The sizes and settling velocities of the flocs were measured individually and averaged separately for Macroflocs and microflocs. Figures used in what follows are the unweighted arithmetic mean values for Macroflocs and microflocs in each sample. The coefficient of variation of settling velocities within a sample was generally between 0.4 and 1.1.

The simultaneous measurement of $d$ and $w_{\mathrm{s}}$ allowed the effective density $\left(\rho_{\mathrm{e}}\right)$ of individual flocs to be calculated from a re-arranged Stokes' Law relationship. Computational techniques originally derived by Fennessy et al. (1997) and modified by Manning (2004), were then applied to calculate individual floc dry mass and the mass settling flux (MSF) distribution for each INSSEV floc sample. 
The full floc data-set measured and interpreted by MD07 comprised 157 observations made using the INSSEV instrument: 91 in situ measurements in the Tamar Estuary, 34 in the Gironde, 11 in the Dollard, and 21 from controlled hydraulic laboratory simulations. For the present study we exclude the laboratory data, seven anomalously dense ( $\left.>1400 \mathrm{~kg} \cdot \mathrm{m}^{-3}\right)$ microfloc data-points thought to be heavy mineral grains, and two anomalously low density $\left(<1010 \mathrm{~kg} \cdot \mathrm{m}^{-3}\right)$ Macrofloc data-points thought to contain a high proportion of organic matter. The relationship between floc size and density (Section 3.4) is based on the remaining data from all three estuaries. Water depths are required for fitting the settling velocity formulae to data, but are not available for any of the Dollard (and a few of the other) measurements, so these data-points were excluded from the latter fitting procedure. This leaves 113 in situ measurements from the Tamar and Gironde, which form the main data-set for calibration of the derived formulae (Section 3.6). Thus data from all three estuaries are used to determine the density-size relationship, but only from two for the main calibration exercise.

\section{Methods}

\subsection{Assumptions}

We make the following assumptions, similar to those made by MD07, about the nature of flocculated mud based partly on the evidence of the MD07 field observations, and partly on established principles of mud properties (e.g. Dyer, 1986, 1989).

1. Flocs are formed from primary particles comprising clay flakes, silt and sand grains, and organic debris. The primary particles are bound together into aggregates by cohesion due to a combination of electrochemical and organic "glue" forces.

2. The floc population can be divided into two classes: microflocs (made up of a loose aggregate of primary particles) and Macroflocs (made up of a loose aggregate of microflocs). Within a particular water sample, each class can be characterised by a single size. The dividing line between microflocs and Macroflocs is empirically set at a spherical-equivalent diameter of $160 \mu \mathrm{m}$.

3. The equilibrium size and settling velocity of microflocs are determined only by the turbulent shear-stress (which controls the fine-scale shear and, in turn, the rates of shear-induced floc aggregation and breakup).

4. The equilibrium size and settling velocity of Macroflocs are determined by the turbulent shear-stress and the overall concentration of suspended particulate matter (SPM).

5. The relative concentrations of microflocs and Macroflocs are determined only by the SPM concentration.

6. Differences in bond strengths between particles due to variations in mineralogy, estuarine water salinity and biological content are small compared with the effects of turbulent shear-stress and SPM concentration and are therefore ignored.

7. The timescales on which floc formation and break-up operate are sufficiently small that, in a tidal estuarine flow, the floc population can be treated as being in quasi-equilibrium, with floc formation almost balanced by break-up, so that a fully time-dependent approach is not necessary.

On this basis, MD07 devised a formulation for the mass settling flux (MSF) comprising seven equations obtained by standard regression analysis applied to the data-set, containing 27 empirical (mostly dimensional) fitting coefficients. The MSF is expressed as a function of SPM concentration and turbulent shear-stress. 
Regarding assumption 2, the demarcation point for the Macrofloc:microfloc fractions was chosen by MD07 at a floc size of $160 \mu \mathrm{m}$ for two main reasons:

i. primarily this was found to be the most statistically significant separation point for the majority of the sediment floc populations in terms of mass settling properties for the original set of 157 samples, where SPM concentrations were as high as $8 \mathrm{~kg} \cdot \mathrm{m}^{-3}$ and numerous large, fast settling macroflocs were observed;

ii. it also now provides computational continuity with numerous studies on flocculation algorithms, settling flux distributions, and floc modelling studies (e.g. Baugh and Manning, 2007; Gratiot and Manning, 2007; Manning and Dyer, 2007; Spearman et al., 2011; Spencer et al., 2010; Winterwerp et al., 2006).

In assumptions 4 and 5 , the effective volumetric concentration might theoretically be a better proxy for concentration than SPM. However, because of the ease of measuring SPM compared with the difficulty and indirectness of measuring the effective volumetric concentration in field studies, like MD07 we have opted for dependency on the SPM concentration.

The quasi-equilibrium assumption 7, also adopted by Van Leussen (1994), Winterwerp et al. (2006) and MD07, permits a considerable simplification of the formulation of $w_{\mathrm{s}}$ and MSF. This ignores any time lag between a change in the flow speed and the response of the floc size and structure: e.g., Verney et al. (2010) showed in laboratory tidal simulations that the floc response could exhibit a lag of more than 20 minutes during floc aggregation, but was almost instantaneous during floc break-up. In most tidal estuary situations assumption 7 is a good approximation. However, it might underestimate the initial deposition rate in cases where the flow velocity decreases abruptly (e.g. ingress of turbulent sediment-laden water into a quiescent harbour) because the predicted settling velocity decreases abruptly instead of slowly, and, vice versa, overestimate it where the velocity increases abruptly (e.g. under a tidal bore).

\subsection{Turbulent energy dissipation}

The turbulence properties of flowing fluids follow well-established and universal relationships (e.g., Hinze, 1975). The rate of production of turbulent kinetic energy (TKE) is the product of the shear-stress $(\tau)$ and the mean velocity gradient $(\partial \mathrm{U} / \partial \mathrm{z})$. The turbulent eddies break into smaller eddies, carrying the TKE to smaller and smaller scales within the inertial sub-range of the spectrum (the eddy-scales for which inertia is dominant and viscosity is negligible). At still smaller scales (the dissipation sub-range), the viscosity of the water exerts a significant force through the shear in the small eddies, giving rise to viscous dissipation of the TKE with an energy dissipation rate $\varepsilon$ per unit mass of water. The size of eddy at which viscous shear forces become important is typified by the Kolmogorov microscale, $\eta$. For eddy-sizes within the dissipation subrange, Kolmogorov argued that the turbulence structure depends only on $\varepsilon$ and the kinematic viscosity $v$ of the fluid, which can be combined by dimensional reasoning to define a characteristic length scale:

$\eta=\left(\frac{v^{3}}{\varepsilon}\right)^{1 / 4}$

Combining $\eta$ with the corresponding Kolmogorov velocity scale, $u_{K}=(v \varepsilon)^{1 / 4}$, provides a characteristic scale for the shear within these small eddies, $G=u_{K} / \eta=(\varepsilon / v)^{1 / 2}$, as mentioned earlier.

For a steady, uniform flow in water of depth $h$, the time-averaged current speed $U(z)$ varies logarithmically with height $z$, the shear stress $\tau(z)$ decreases linearly with $z$ from its value at the bed to zero at the water 
surface, and the overall dissipation rate $(\varepsilon)$ of TKE per unit mass of water is equal to the generation rate by the large eddies $(\tau \partial U / \partial z)$. The bed shear-stress $T_{0}$ and friction velocity $u_{*}$ can be derived from the observed shear-stress $\tau(z)$ (typically measured at height $z=0.5-0.6 \mathrm{~m}$ in the MD07 data-set) through $\tau_{0}=\rho u_{*}{ }^{2}=\tau(z) / \xi$ and the logarithmic velocity profile gives $\partial U / \partial z=u_{*} / K z$. Thus under steady, uniform conditions, and neglecting diffusion of TKE (Hinze, 1975; Nezu and Nakagawa, 1993):

$$
\varepsilon=\frac{\tau}{\rho} \frac{\partial U}{\partial z}=\frac{u_{*}^{3} \xi}{\kappa Z}
$$

\subsection{Floc properties}

There is wide agreement that the largest floc sizes are related to the Kolmogorov microscale (e.g. Van Leussen, 1988; Elimelich et al., 1995; Winterwerp, 1999). Verney et al. (2010) found in laboratory tests that the mean floc size was equal to about $\eta / 4$ and the maximum floc size (taken as the $90^{\text {th }}$ percentile) was equal to about $\eta / 3$, with a range of variation around both these values. Cuthbertson et al. (2010) found in their laboratory tests that the peak floc size (taken as the $95^{\text {th }}$ percentile) was a little larger than $\eta / 3$.

We use similar (but not identical) assumptions to those of Winterwerp et al (2006): (a) that the mean diameter of Macroflocs, $d_{\mathrm{M}}$, is proportional to $\eta$, and (b) $d_{\mathrm{M}}$ has a power-law relationship with the dimensionless concentration, $c$, expressed as mass of solid per mass of suspension. Thus:

$$
d_{M}=\alpha_{M} \eta c^{k}
$$

where $\alpha_{M}$ and $k$ are dimensionless coefficients. In order to preserve dimensional homogeneity in Eq (3) we use the dimensionless concentration $c=$ SPM $/ \rho$, where SPM is mass of solid per volume of suspension, in preference to using SPM directly. For simplicity, and consistent with the aims of the model, we ignore other factors that might influence the floc diameter such as the time history of the flow. Since the settling velocity of Macroflocs, $w_{S M}$, is slow (Reynolds numbers $w_{S M} d_{M} / v<2.2$ ), the Stokes law of settling is a good approximation:

$$
w_{s M}=\frac{\left(s_{e M}-1\right) g d_{M}^{2}}{18 v}
$$

in which $s_{\mathrm{eM}}=\rho_{\mathrm{eM}} / \rho$, and $\rho_{\mathrm{em}}$ is the effective density of the Macroflocs. Similar arguments apply to microflocs, with equation (3) replaced with $d_{\mu}=\alpha_{\mu} \eta$ (no dependence on concentration) and with subscript $\mu$ replacing $M$ throughout in equation (4).

\subsection{Dependence of floc density on diameter}

The excess effective floc density is known to decrease with increasing floc-size. Elimelich et al. (1995), Winterwerp (1999), Winterwerp et al. (2006) and others assumed that flocs have a fractal nature, in order to establish a power-law relationship between floc density and floc size for a continuum of floc sizes. In the present treatment we do not invoke fractal behaviour of flocs per se, but observe that analogous power-law relationships between excess effective density and diameter give reasonably good fits to the MD07 data when separated into the microfloc (effective density $=\rho_{\mathrm{e \mu}}$ ) and Macrofloc (effective density $=\rho_{\mathrm{em}}$ ) populations. The excess effective density is seen to decrease with diameter more steeply for microflocs than for Macroflocs (Fig. 1), approximating to power-law relationships. From log-log regressions, these are: ( $\rho_{\mathrm{e} \mu}-$ 
$\rho)=1.91 \times 10^{5} \cdot d_{\mu}^{-1.56}$ for microflocs and $\left(\rho_{\mathrm{eM}}-\rho\right)=2.63 \times 10^{3} \cdot d_{\mathrm{M}}{ }^{-0.664}$ for Macroflocs, with densities in $\mathrm{kg} \cdot \mathrm{m}^{-3}$ and diameters in $\mu \mathrm{m}$. Although there is considerable scatter, the $R^{2}$ values of 0.371 and 0.147 are both significant at the 99 per cent confidence level. The fitted coefficients \pm their standard errors are: for microflocs (multiplier $=10^{(5.281 \pm 0.350)}$, slope $\left.=-1.558 \pm 0.175\right)$, and for Macroflocs (multiplier $=10^{(3.419 \pm 0.325)}$, slope $=-0.663 \pm 0.136$ ). When Fig. 1 is subdivided by estuary (not shown), no systematic distinction between the Tamar, Gironde and Dollard can be detected.

Making use of the connection between fractal dimension $\left(n_{f}\right)$ and the power-law dependence of excess density on diameter (Winterwerp, 1999), the powers obtained from the log-log regressions correspond to $n_{f}=$ $1.442 \pm 0.175$ for microflocs and $n_{f}=2.337 \pm 0.136$ for Macroflocs. These values lie either side of the general-purpose value $\mathrm{n}_{\mathrm{f}}=2$ advocated by Winterwerp (1999).

In physical terms, these relationships correspond to the mean spacing between particles in a floc increasing with the number of particles constituting the floc. Using this rationale, the density-dependence of microflocs can be re-written in dimensionally homogeneous form as:

$$
\frac{s_{e \mu}-1}{s-1}=\beta_{\mu}\left(\frac{d_{\mu}}{d_{1}}\right)^{-1.56}
$$

where $s_{\mathrm{e} \mu}=\rho_{\mathrm{e} \mu} / \rho, s=\rho_{\mathrm{s}} / \rho, \rho_{\mathrm{s}}$ is the mineral density of the primary particles, $d_{1}$ is the (notional) diameter of the primary particles, and $\beta_{\mu}$ is a dimensionless coefficient. Likewise, taking Macroflocs to be made up of assemblages of microflocs, the density-dependence of Macroflocs can be re-written as:

$$
\frac{s_{e M}-1}{\bar{s}_{e \mu}-1}=\beta_{M}\left(\frac{d_{M}}{\bar{d}_{\mu}}\right)^{-0.664}
$$

where $\bar{s}_{e \mu}$ is the mean relative effective density of the 113 microfloc data, $\bar{d}_{\mu}$ is their mean effective diameter, and $\beta_{\mathrm{M}}$ is a dimensionless coefficient. We take standard values of $s=2.6368, d_{1}=10^{-5} \mathrm{~m}(10 \mu \mathrm{m})$, $\bar{s}_{e \mu}=1.15$ and $\bar{d}_{\mu}=10^{-4} \mathrm{~m}(100 \mu \mathrm{m})$, which should be used in all applications of the method. Since $\bar{d}_{\mu}=10$ $d_{1}$ and $\left(\bar{s}_{e \mu}-1\right)=0.0915(s-1)$, Eq (6) could alternatively be written in terms of primary particle properties.

\subsection{Floc settling velocities}

We express the settling velocities directly in terms of the TKE dissipation rate, $\varepsilon$, to allow direct application of the formulae in flow/sediment models that make use of $k-\varepsilon$ turbulence closure (where $k$ is TKE). In applications where modelled $\varepsilon$-profiles are not available, $\varepsilon$ can be obtained from Eq (2) under the assumption that tidal flows are approximately quasi-steady and uniform.

Taking first the case of Macroflocs, and employing the connection between Macrofloc diameter and Kolmogorov microscale ( $\mathrm{Eq} 3$ ) and the connection between floc density and diameter (Eq 6) in the Stokes formula (Eq 4) yields an expression for the Macrofloc settling velocity of the form:

$$
w_{s M}=B_{M}\left(\bar{s}_{e \mu}-1\right)\left(\frac{\varepsilon \bar{d}_{\mu}^{4}}{v^{3}}\right)^{0.166} g c^{2.672 k}\left(\frac{v}{\varepsilon}\right)^{1 / 2}
$$


where coefficient $B_{M}$ combines the dimensionless quantities $\alpha_{M}, \beta_{M}$ and 18 .

Equation (7) shows $w_{\mathrm{SM}}$ increasing with $c$ and decreasing continuously with $\varepsilon$, and hence $\tau$. By contrast, the observations of MD07 show $W_{S M}$ increasing with $\tau$ for small $\tau$, and reaching a maximum before decreasing with $\tau$ for large $\tau$. Winterwerp et al. (2006) attributed the departure of the data from the behaviour shown by Eq (7) to the limited residence time during which flocs can form, which at small shear-stresses is small compared with the development time of the flocs. Their solution of a differential equation for the rate of growth of (Macro)floc diameter contained a function of $\left(\tau^{9 / 8} h\right)$ which reduced $w_{S M}$ for cases with small shearstress or depth. A simpler expedient is adopted here, in which Eq (7) is multiplied by an exponential attenuation factor dependent on $[\tau(z) / \rho]^{1 / 2}=u_{*} \xi^{1 / 2}$ (see Section 3.2) representing this effect. Equation (7) then becomes

$w_{s M}=B_{M}\left(\bar{s}_{e \mu}-1\right)\left(\frac{\varepsilon \bar{d}_{\mu}^{4}}{v^{3}}\right)^{0.166} g c^{2.672 k}\left(\frac{v}{\varepsilon}\right)^{1 / 2} \exp \left[-\left(\frac{u_{*_{s M}}}{u_{*} \xi^{1 / 2}}\right)^{N}\right]$

where $B_{\mathrm{M}}, k, u_{*_{\mathrm{SM}}}$ and $N$ are optimisable coefficients.

The equation for microflocs is assumed to be of similar form to Eq (8) but with no dependence on concentration. This is based on the similarities between the curves for Macroflocs and microflocs illustrated by MD07, although the case is more tenuous because the link between microfloc diameter and $\eta$ is less well established. MD07 found that the most prominent difference to be revealed by their statistical multiple regression analysis when comparing their algorithms for settling velocity of Macroflocs and microflocs was the negligible influence of SPM concentration variations on the latter. Including the SPM concentration term in the microfloc algorithm in the MFSV method did not significantly improve the algorithm representation of the data (in terms of statistical $R^{2}$ ). This is possibly due to the microflocs being the building blocks from which the macroflocs are formed. Making use of Eq (5) yields

$w_{s \mu}=B_{\mu}(s-1)\left(\frac{\varepsilon d_{1}^{4}}{v^{3}}\right)^{0.39} g\left(\frac{v}{\varepsilon}\right)^{1 / 2} \exp \left[-\left(\frac{u_{* \mu}}{u_{*} \xi^{1 / 2}}\right)^{n}\right]$

where $B_{\mu}, u_{* s \mu}$ and $n$ are optimisable coefficients.

\subsection{Calibration of coefficients}

The optimisable coefficients in Eqs (8) and (9) have been obtained by least-squares regression against the MD07 data for Macroflocs and microflocs respectively, using the standard values of $s=2.6368, d_{1}=10^{-5} \mathrm{~m}$, $\bar{s}_{e \mu}=1.15$ and $\bar{d}_{\mu}=10^{-4} \mathrm{~m}$. The four coefficients $\left(B_{\mathrm{M}}, k, u_{*_{\mathrm{M}}}\right.$ and $\left.N\right)$ in Eq (8) were optimised against the measurements of Macrofloc settling velocity in the MD07 data-base to minimise the sum-of-squared errors, $\sum_{\text {obs }}\left(\mathrm{w}_{\text {sM pred }}-\mathrm{w}_{\text {sM obs }}\right)^{2}$ , between the predicted (pred) and observed (obs) $W_{\mathrm{SM}}$, using the 113 data-points that have measured depths. A similar least-squares optimisation of the coefficients $\left(B_{\mu}, u_{*}\right.$ and $\left.n\right)$ in Eq (9) was performed against the MD07 microfloc data. The optimised values are: $B_{\mathrm{M}}=0.860, k=0.0825, u_{* \mathrm{M}}=$ $0.067 \mathrm{~m} . \mathrm{s}^{-1}, N=0.463$, and $B_{\mu}=0.363, u_{*_{\mathrm{s} \mu}}=0.025 \mathrm{~m} . \mathrm{s}^{-1}, n=0.66$. 
These coefficients can be used directly in Eqs (8) and (9) for applications with $k-\varepsilon$ (and other suitably complex) flow/sediment models. For other applications approximating to uniform steady flow (e.g. tidal flows), $\varepsilon$ can be expressed by Eq (2) and the optimised coefficients inserted in Eqs (8) and (9) to give the Macrofloc and microfloc settling velocities in the forms:

$$
\begin{aligned}
& w_{s M}=0.095\left(\frac{u_{*}^{3} \xi \bar{d}_{\mu}^{4}}{v^{3} z}\right)^{0.166} g c^{0.22044}\left(\frac{v z}{u_{*}^{3 \xi}}\right)^{1 / 2} \exp \left[-\left(\frac{u_{*_{S M}}}{u_{*} \xi^{1 / 2}}\right)^{0.463}\right] \\
& w_{s \mu}=0.5372\left(\frac{u_{*}^{3} \xi d_{1}^{4}}{v^{3} z}\right)^{0.39} g\left(\frac{v z}{u_{*}^{3 \xi}}\right)^{1 / 2} \exp \left[-\left(\frac{u_{* s \mu}}{u_{*} \xi^{1 / 2}}\right)^{0.66}\right]
\end{aligned}
$$

In Eqs (10) and (11), $u_{*}$ must be in $\mathrm{m} \mathrm{s}^{-1}$ to match the units of $u_{* \mathrm{sM}}=0.067 \mathrm{~m} \cdot \mathrm{s}^{-1}$ and $u_{*_{\mathrm{s} \mu}}=0.025 \mathrm{~m} \cdot \mathrm{s}^{-1}$, and the standard values of $\bar{d}_{\mu}=10^{-4} \mathrm{~m}$ and $d_{1}=10^{-5} \mathrm{~m}$ must be used. These values have not been substituted in, so as to retain dimensional homogeneity.

\subsection{Mass settling flux}

The main requirement for knowing the settling velocity of mud flocs is as an aid to calculating the mass settling flux (MSF). This is the rate at which mud is deposited towards the bed, usually measured in units of $\mathrm{kg} \cdot \mathrm{m}^{-2} \cdot \mathrm{s}^{-1}$, and given by the product of the concentration (as mass per volume) and the settling velocity. In the present two-population model with Macroflocs and microflocs, the MSF is the sum of the two individual settling fluxes.

If we define $r$ as the proportion of the total mass of SPM made up of Macroflocs, it might be expected a priori that $r$ would depend primarily on the intensity of turbulence, which is thought to govern the aggregation and break-up of flocs. However, the observed values of $r$ show only weak correlations with either the shearstress $\left(R^{2}=0.107\right)$, or its logarithm $\left(R^{2}=0.126\right)$; but, as found by MD07, $r$ has a stronger correlation with the logarithm of SPM concentration $\left(R^{2}=0.558\right)$. Furthermore, consistent with our assumption 7 (quasiequilibrium) we do not include floc kinetics that would introduce a time-history into the relationship. We therefore follow the interpretation of the data made by MD07, namely that the relative concentrations of microflocs and Macroflocs are determined only by the SPM concentration. With these considerations, if we define $X=\log _{10} c+6$, (numerically equivalent to $\log _{10}(\mathrm{SPM})$ if SPM is in mg. ${ }^{-1}$ ), examination of the MD07 data-set (Fig. 2) suggests the following empirical relationship:

$$
\begin{aligned}
r & =0.1 & & \text { for } X<0 \\
& =0.1+0.221 X & & \text { for } 0 \leq X<4.07 \\
& =1 & & \text { for } X \geq 4.07
\end{aligned}
$$

Equation (12) is weighted so as to pass more accurately through the high-concentration data-points than those at small SPM, since the former contribute the most to the MSF, and has a coefficient of determination $\mathrm{R}^{2}=0.907$. Subdivision of the data according to shear-stress (Fig. 2a) shows no systematic variation of $r$ with shear-stress, confirming the dependence only on SPM concentration. Likewise, the data-points for Tamar and Gironde estuaries do not form separate groups (Fig. 2b), showing that the same equation can be applied to both estuaries.

We define the mass-averaged settling velocity $w_{\mathrm{s}, \mathrm{av}}$ as: 
$W_{\mathrm{s}, \mathrm{av}}=\max \left[r \cdot w_{\mathrm{sM}}+(1-r) \cdot w_{\mathrm{s} \mu}, 0.2 \mathrm{~mm} \cdot \mathrm{s}^{-1}\right]$

with $r$ given by Eq (12), $w_{\mathrm{sM}}$ by Eq (8) or (10) and $w_{\mathrm{s \mu}}$ by Eq (9) or (11). Based on the MD07 observations we impose a pragmatic minimum value of $w_{\mathrm{s}, \mathrm{av}}=0.2 \mathrm{~mm} \cdot \mathrm{s}^{-1}$, corresponding to the settling velocity of small, tightly-bound microflocs. This value is smaller than any observed values in the MD07 data-base, and hence does not influence the calibration of the coefficients. In cases where $u_{*}=0$ (no flow), or $z=0$ (sea-bed), or $\xi=0$ (water surface), Eqs (8) and (9) [or (10) and (11)] do not apply, and $w_{\mathrm{s}, \mathrm{av}}=0.2 \mathrm{~mm} \cdot \mathrm{s}^{-1}$ should be used instead. The total mass settling flux can then be written as:

$\mathrm{MSF}=w_{\mathrm{s}, \mathrm{av}} c \rho$

Root-mean square residual errors of the variables $\mathrm{w}_{\mathrm{SM}}, \mathrm{w}_{\mathrm{s \mu}}, \mathrm{w}_{\mathrm{s}, \mathrm{av}}, \mathrm{r}$ and MSF for the 113 calibration data relative to the fitted equations 10 to 14 are given in Table 1. A more detailed error analysis is given in Section 4.

Equations (8) to (14) comprise the Soulsby-Manning 2012 (SM12) formulation, using Eqs (8) and (9) if $\varepsilon$ has been modelled, or Eqs (10) and (11) if not.

\section{Results}

To assess the accuracy and generality of the SM12 method, we have calculated various measures of performance. Two of these are based on analogous tests by Winterwerp et al. (2006) and MD07 of their own prediction methods.

\subsection{Predicted versus observed settling velocities}

Plots of predicted versus observed settling velocities for Macroflocs (Fig 3a) and microflocs (Fig 3b) show a reasonable clustering around the 1:1 line irrespective of estuary and over a wide range of settling velocities, although there is a tendency for the predicted values of $\mathrm{w}_{\mathrm{s} \mu}$ to level off at a maximum of about $1.0 \mathrm{~mm} . \mathrm{s}^{-1}$, whereas the observations show a scatter between 0.5 and $1.5 \mathrm{~mm} . \mathrm{s}^{-1}$ in this region. The proportion of predicted settling velocities lying within a factor of two of the observations is 98.2 per cent for the Macroflocs and 100 per cent for the microflocs. The corresponding figures for a factor of 1.5 are 91.2 per cent for the Macroflocs and 94.7 per cent for the microflocs.

\subsection{Settling velocity statistics compared with Winterwerp et al. (2006)}

Winterwerp et al. (2006) proposed a formula for the settling velocity of Macroflocs (but not microflocs), and compared their predictions with observed values for the Tamar (which form part of the total MD07 data-set). They computed measures of goodness-of-fit in two ways: the absolute standard deviation $\left(\sigma_{\mathrm{abs}}\right)$ between predicted and measured values of settling velocity, and the relative standard deviation $\left(\sigma_{\text {rel }}\right)$ in which the deviation of each data-point is divided by the measured value. They divided the data into classes of concentration range, and also gave values for all the data together. The same procedure has been followed using the SM12 method with combined data from the Tamar and Gironde estuaries. Statistics are given (Table 2) for both Macroflocs (Eq 10) and for the more useful measure of mass-averaged settling velocity $w_{\mathrm{s}, \mathrm{av}}(\mathrm{Eq} 13)$. 
The Macrofloc standard deviations for "All data" ( $\left.\sigma_{\mathrm{abs}}=0.49 \mathrm{~mm} \cdot \mathrm{s}^{-1}, \sigma_{\mathrm{rel}}=25 \%\right)$ are slightly better for the SM12 method than those of Winterwerp et al. $\left(0.69 \mathrm{~mm} \cdot \mathrm{s}^{-1}, 31 \%\right)$. All the other Macrofloc statistics are also better than those of Winterwerp et al. apart from $\sigma_{a b s}$ for $\mathrm{SPM}<0.1$ and $0.1<\mathrm{SPM}<0.2$, and $\sigma_{\text {rel }}$ for $\mathrm{SPM}<$ 0.1 .

he SM12 statistics for $w_{\mathrm{s}, \mathrm{av}}$ also show that the standard deviations for "All data" $\left(0.40 \mathrm{~mm} . \mathrm{s}^{-1}, 27 \%\right)$ are appreciably smaller than those of Winterwerp et al. for Macroflocs. For SPM concentrations between 0.1 $\mathrm{kg} \cdot \mathrm{m}^{-3}$ and $4.0 \mathrm{~kg} \cdot \mathrm{m}^{-3}$ the $\sigma_{\text {abs }}$ values for the SM12 method are typically about half those for the Winterwerp et al. (2006) method, indicating that the inclusion of the microfloc population gives a distinct improvement in prediction accuracy.

\subsection{Mass settling flux statistics compared with MD07}

MD07 plotted observed versus predicted MSF for their own floc model and four other models (constant $w_{\mathrm{s}}=$ 0.5 and $5.0 \mathrm{~mm} \cdot \mathrm{s}^{-1}$, a power-law regression between $w_{\mathrm{s}}$ and SPM, and the method of Van Leussen, 1994) for the 157 cases in their database (including 14 laboratory data). Figure 4a shows a similar plot (but with 'observed' as the abscissa) for the SM12 method applied to the 113 field data with measured depths. The predicted mass settling fluxes using the SM12 method show very good agreement with the observed MSF. No systematic difference is seen between the Tamar and Gironde estuaries, and 98.2 per cent of the predicted MSF agree to within a factor of two of the observed values. The fit does not progressively deviate for either small or large MSF, and compares favourably with four of the five methods plotted by MD07, with only the MFSV method having a comparable accuracy to the SM12 method.

MD07 calculated the cumulative total MSF (i.e. the summation of all 157 individual MSF values) both from their data and from the predictions using the five methods M1 to M5 (defined in Table 3). They presented three measures of performance of the methods: the mean error and standard deviations of the predictions and the ratio of predicted to observed MSF. We follow this in Table 3, but, in order to make a fair comparison with the SM12 method, the statistics for the other five methods have been re-calculated using only the 113 field data with depths rather than the 157 laboratory and field data used in the original MD07 table (though differences are small). Two sets of statistics are given for the SM12 model for statistics versus the calibration data (SM12-Cal) and versus independent data (SM12-Ind, see Section 4.5). Models M1, M4, M5 were also calibrated against the test data. The SM12-Cal statistics compare well with those for the MFSV method (M1), giving closer agreement with the observed cumulative MSF, but larger mean (absolute) error and standard deviation. In addition, for almost all the statistics, the SM12 method performs better than methods M2 - M5. The predicted cumulative total MSF by the SM12 method is only $1.3 \%$ smaller than the observed value, which is better than all of the other methods.

\subsection{Variation of MSF with height}

We also examine how well the new model predicts the variation of MSF with height $z$. The reduced MD07 data-set covers the range of water depths $0.9 \mathrm{~m}$ to $9.2 \mathrm{~m}$, which when combined with the measuring heights of $0.5-0.6 \mathrm{~m}$, yields relative depths in the range $0.05<z / h<0.6$. The ratios (predicted MSF)/(observed MSF) plotted for each data-point versus $z / h$ (Figure 5, open symbols) scatter fairly evenly about the line of perfect agreement $(\mathrm{pred} / \mathrm{obs})=1$. Grouping the data into bands of $z / h$ of width 0.1 , the median values in each band (Fig 5, filled symbols) cluster tightly about the line (pred/obs) $=1$, indicating that the $z$-dependence of the data is well-represented by the SM12 method for heights up to more than mid-depth. (Median values are used because the arithmetic mean of a set of ratios is a biased estimator.) 


\subsection{Comparison with independent data-sets}

Having fixed the coefficients in the SM12 equations by calibrations against data from the Tamar and Gironde, we now test the method against two independent sets of observations without altering these coefficients. This gives an indication of how well the method will perform as an 'off-the-shelf' tool when confronted with an unfamiliar estuary. Both data-sets were collected by A.J.M. using the INSSEV equipment, and analysed using the same procedures as for the calibration data. The total number of independent data-points (105) is similar to that of the calibration data (113).

The first test data-set comprises 50 water samples forming a complete tidal cycle of observations in the Tamar estuary collected on 15th April 2003 (Bass et al., 2006; MD07) at the same site near Calstock as the 1998 measurements used in the SM12 calibration data. These data, which were used by MD07 to test the performance of their MFSV model, are from one of the calibration estuaries and hence not entirely independent. However, the 2003 Tamar data were collected three days before high spring tides, with $\sim 0.4 \mathrm{~m}$ higher range than the spring tides observed during the 1998 measurements, which nearly doubled the observed turbulent shear stresses in the nearbed region. Time-series through the tidal cycle of the observed and SM12-predicted mass settling flux (Fig. 6a) show that the SM12 model agrees well with the observations, simulating most of the features of the tidal variation in MSF accurately. The SM12 model has a similar level of accuracy to the MFSV model plotted by MD07. The integrated (absolute) MSF through the tidal cycle was over-estimated by $21 \%$, and $88 \%$ of the predictions lay within a factor of two of the observed MSF.

The second test data-set comprises 55 data from three days of observations in the Lower Scheldt estuary (17th - 19th February 2005), with between six and eleven hours of data collection per day. This data-set was used as test data by Winterwerp et al. (2006) to test their settling velocity model. Fig. $6 \mathrm{~b}$ shows the tidal variations of observed and predicted MSF. Values of MSF are generally smaller than those observed in the Tamar (Fig. 6a). The degree of agreement is rather less good for the Scheldt than the Tamar data-set, although the main features are simulated correctly, but with a tendency for overprediction by a factor of between one and two.

Winterwerp et al. (2006) recalibrated the coefficients in their model to match the Scheldt data, and did not present performance results for their 'standard' coefficients. However, we chose to apply our model with the originally calibrated coefficients, in order to gain insight into the performance of the 'standard' model if it were applied to an estuary which has no settling velocity data available. Winterwerp et al. (2006) quoted statistics of model performance for $\mathrm{W}_{\mathrm{sM}}$ from their recalibrated model of $\sigma_{\mathrm{abs}}=0.50 \mathrm{~mm} . \mathrm{s}^{-1}$ and $\sigma_{\mathrm{rel}}=49 \%$ (c.f. Sec. 4.2 and Table 2). Comparable figures for $w_{\mathrm{s}, \mathrm{av}}$ from our SM12 model with the standard values of the coefficients are $\sigma_{\mathrm{abs}}=0.59 \mathrm{~mm} \cdot \mathrm{s}^{-1}$ and $\sigma_{\text {rel }}=77 \%$. These errors are larger than those of Winterwerp et al., but are nevertheless a creditable performance for a 'standard' model. For comparison, the "All data"standard deviations for the 2003 Tamar observations are $\sigma_{\text {abs }}=0.60 \mathrm{~mm} \cdot \mathrm{s}^{-1}$ and $\sigma_{\mathrm{rel}}=59 \%$. The statistics for Scheldt and 2003 Tamar, combined together and subdivided by SPM categories (Table 2, bottom row), lie in the ranges $0.34<\sigma_{\text {abs }}<0.98 \mathrm{~mm} . \mathrm{s}^{-1}$ and $8<\sigma_{\text {rel }}<92$ percent. For comparison, similar statistics tabulated by Winterwerp et al. for their recalibrated model applied to the Scheldt alone (where SPM $<0.3 \mathrm{~kg} \cdot \mathrm{m}^{-3}$ ) lie in the ranges $0.39<\sigma_{\text {abs }}<0.66 \mathrm{~mm} . \mathrm{s}^{-1}$ and $40<\sigma_{\text {rel }}<56$ percent.

The integrated (absolute) MSF for the Scheldt data was over-estimated by $19 \%$, and $73 \%$ of the predictions lay within a factor of two of the observed MSF. A comparison of the predicted MSF with the observed values (Fig 4b) for the combined Scheldt and 2003 Tamar data shows reasonable agreement (79\% of predictions within factor-of-two of observations), although (not surprisingly) rather less good than for the calibration data 
(Fig. 4a). There is no systematic distinction between the Scheldt and 2003 Tamar data-points, indicating that the SM12 method works equally well in these two estuaries.

Statistical tests of the accuracy of the SM12 method when applied to the independent data from Tamar and Scheldt (Table 3, column SM12-Ind) are larger than the equivalent figures for the calibration data (SM12$\mathrm{Cal}$ ), for the reasons given above. When comparing these figures with those for models M1-M5 it should be recalled that the statistics for models $\mathrm{M} 1, \mathrm{M} 3$ and $\mathrm{M} 4$ are for models calibrated against the test data. The figures for SM12-Ind give an indication of the accuracy to be expected when applying the model in an uncalibrated situation.

\section{Discussion}

The Soulsby-Manning 2012 (SM12) method has a number of advantages over the already successful MFSV method of MD07:

- The inclusion of physical processes in the formulation should, in principle, permit a broader range of applicability.

- Alternative methods have been provided for use with $k-\varepsilon$ models (using component Eqs 8 and 9) and simpler cases (using alternative Eqs 10 and 11).

- The number of equations has been reduced from seven to five, and the number of empirical coefficients from 27 to 11.

- In both models, the coefficients are assumed to be applicable to a wide range of estuaries, although they could optionally be re-calibrated to match individual estuaries if sufficient data are available.

- These equations are continuous over the entire validated range of shear-stress, concentration, height and depth, which obviates the interpolation procedure required in the MFSV method which caused unrealistic wiggles in the curves presented by MD07.

- The height-dependence of the formulation has been tested against data, from the bed up to mid-depth, and no systematic deviations were found.

- The level of agreement with field data from the Tamar and Gironde estuaries is comparable with the MFSV method and better than four other models tested by MD07 (Table 3).

The SM12 model has some commonalities with that of the Winterwerp et al. (2006) model. Both models have floc size proportional to $\eta$ and a power of concentration, they both have power-law relationships between excess floc density and floc diameter, and they both use Stokes-like formulae for $w_{\mathrm{s}}$. The main differences are: (a) Winterwerp et al. take only one representative floc size whereas SM12 takes two sizes (microflocs and Macroflocs), (b) Winterwerp et al. assume fractal behaviour for all floc sizes whereas SM12 fits power-laws for density to microflocs and Macroflocs separately, and (c) the two models use different exponential decay terms to reduce $w_{s}$ for small $\tau$.

The SM12 model looks promising for use in computational models of muddy estuaries. Some comments on applicability are relevant. So far, the method has been calibrated and tested against data from only a few Northern European estuaries, and its generality for use in other situations is not known. If a sufficiently large set of data from other estuaries was available, the coefficients could be re-calibrated either separately for the study case, or combined with the previous data. In the absence of site-specific data, the coefficients quoted above can be used, with due caution given to the results. 
The assumption in the SM12 method about the diameter of the primary particles that are the building blocks for microflocs (Section 3.4) can be compared with observations by Lee et al. (2012) of the particle size distributions (PSDs) of suspended fine material using a LISST particle sizer at $2 \mathrm{~m}$ above the bed at an open marine site. They found PSDs with 1-4 modal peaks, depending on the hydrodynamic conditions, which they characterised in terms of discrete aggregate groups of primary particles, flocculi, microflocs and Macroflocs. Our notional primary particle size $d_{1}=10 \mu \mathrm{m}$ lies within the upper limit of their combined size range of primary particles and flocculi, which provides confidence that this assumption in the SM12 model is appropriate.

Pejrup and Mikkelsen (2010) explored the correlation between measurements of settling velocities from three North European sites and corresponding values of SPM and G. Inclusion of both parameters in a predictive algorithm improved the description of variations in settling velocity, although they concluded that calibration was required for specific estuaries before use.

Whilst we consider the current method is an improvement over the MFSV and other existing methods it is still recognised good practice in studies to compare results from different methods, to undertake sensitivity testing and where possible validate the results with water column measurements or, for example, records of sedimentation.

\section{Conclusions}

We have developed a new formulation (SM12, Eqs 8-14) for the settling velocities and mass settling fluxes of flocculated estuarine mud by extending the two-class microfloc/Macrofloc empirical model of Manning and Dyer (2007) through physical reasoning. This is based on a linear relationship between floc diameter and the Kolmogorov microscale, a power-law dependence of (Macro)floc diameter on SPM concentration, and power-law relationships between floc effective density and floc size, separately for microflocs and Macroflocs (Fig. 1, Eqs 5 and 6). The resulting formulae for the settling velocity of Macroflocs and microflocs (Eqs 8 and 9) are written in terms of the dissipation rate of turbulent kinetic energy, $\varepsilon$, making them well-suited for use in computational models of estuaries that employ $k-\varepsilon$ turbulence closure. The coefficients in the formulae have been optimised using a least-squares technique calibrated against the 113 MD07 floc data from the Tamar and Gironde estuaries for which water depth was measured. The resulting coefficients are: $B_{\mathrm{M}}=0.860, k=$ $0.0825, u_{* \mathrm{sM}}=0.067 \mathrm{~m} . \mathrm{s}^{-1}, N=0.463, B_{\mu}=0.363, u_{* \mathrm{~s} \mu}=0.025 \mathrm{~m} . \mathrm{s}^{-1}, n=0.66$, taken together with standard

values of: $s=2.6368, d_{1}=10^{-5} \mathrm{~m}, \bar{s}_{e \mu}=1.15$ and $\bar{d}_{\mu}=10^{-4} \mathrm{~m}$. For estuarine models without $k-\varepsilon$ turbulence closure, or for analytical purposes, Eqs (10) and (11) can be used if a uniform-steady assumption is adequate.

The division of the total suspended concentration into the proportion $r$ attributable to Macroflocs (Eq 12), and hence the proportion (1-r) attributable to microflocs, leads to expressions for the mass-averaged settling velocity (Eq 13) and the total Mass Settling Flux (MSF, Eq 14).

Various measures of performance have been calculated, and the new formulations compare well with the methods of Winterwerp et al. (2006) (Table 2) and MD07 and four other methods (Table 3). The heightdependence of the prediction formulae for the MSF compares well with data (Fig. 5) for all heights up to the maximum available (a little higher than mid-depth).

Further tests against independent data from the Tamar and Lower Scheldt estuaries, applying the SM12 model without re-calibration, gave good agreement (generally within a factor two) of predictions against 
observations (Fig. 4b). Comparisons of the predicted and observed mass settling fluxes for tidal time-series for the Tamar and Scheldt reproduced most of the features of the time variation in MSF (Figs 6a,b).

The SM12 method is well-suited to application in computational models of estuarine dynamics with high-level closures and also in simpler cases.

\section{Acknowledgements}

This research was funded by the Company Research Programme of HR Wallingford as project no. DDY0409. The 1998 Tamar data collection was funded under EC MAST contract MAS3-CT97-0082 COSINUS. The 2003 Tamar data collection was funded under Natural Environmental Research Council (UK) contract No. NER/M/S/2002/00108. The Gironde data collection was funded under EC TMR contract No. ERBFMRXCT970111 SWAMIEE. The Dollard data collection was funded under EC MAST contract MAS3CT95-0022 INTRMUD. The Scheldt data collection was funded by Ministerie van de Vlaamse Gemeenschap, Belgium.

\section{References}

Bass, S.J., Manning, A.J., Dyer,K.R., 2006. Preliminary findings from a study of the upper reaches of the Tamar Estuary, UK, throughout a complete tidal cycle: part I. Linking sediment and hydrodynamic cycles. In: Maa, J.P.-Y., Sandford, L.P., Schoelhamer, D.H. (Eds.), Coastal and Estuarine Fine Sediment Processes Proc. in Marine Science, INTERCOH-2003. Elsevier, Amsterdam, pp. 1-14.

Baugh, J.V., Manning, A.J., 2007. An assessment of a new settling velocity parameterisation for cohesive sediment transport modelling. Continental Shelf Research, doi:10.1016/j.csr.2007.03.003.

Cuthbertson, A.J.S., Dong, P., Davies, P.A., 2010. Non-equilibrium flocculation characteristics of fine-grained sediments in grid-generated turbulent flow. Coastal Engineering 57(4), 447-460.

Dronkers, J., Van Leussen, W. (Eds.), 1988. Physical Processes in Estuaries. Springer-Verlag, Berlin, Germany.

Dyer, K.R., 1986. Coastal and Estuarine Sediment Dynamics. Wiley \& Sons, Chichester, UK.

Dyer, K.R., 1989. Sediment processes in estuaries: future research requirements. Journal of Geophysical Research 94(C10), 14327-14339.

Dyer, K.R., Bale, A.J., Christie, M.C., Feates, N., Jones, S., Manning, A.J., 2002. The turbidity maximum in a mesotidal estuary, the Tamar estuary, UK. Part II: The floc properties. In: Winterwerp, J.C., Kranenburg, C. (Eds.), Fine Sediment Dynamics in the Marine Environment - Proceedings. in Marine Science 5., Elsevier, Amsterdam, pp. 219-232.

Dyer, K.R., Christie, M.C., Feates, N., Fennessy, M.J., Pejrup, M., van Der Lee, W., 2000. An investigation into processes influencing the morphodynamics of an intertidal mudflat, the Dollard estuary, The Netherlands: I. Hydrodynamics and suspended sediment. Estuarine \&. Coastal Shelf Science, 50, 607-625.

Eisma, 1986. Flocculation and de-flocculation of suspended matter in estuaries. Netherlands Journal of Sea Research 20(2/3), 183-199.

Elimelich, M., Gregory, J., Jia, X., Williams, R.A., 1995. Particle Deposition and Aggregation: Measurement, Modelling and Simulation. Butterworth-Heinemann, Woburn, MA. 
Fennessy, M.J., Dyer, K.R. and Huntley, D.A., 1994. INSSEV: an instrument to measure the size and settling velocity of flocs in-situ. Marine Geology 117, 107-117.

Fennessy, M.J., Dyer, K.R., Huntley, D.A., Bale, A.J., 1997. Estimation of settling flux spectra in estuaries using INSSEV. In: Burt, N., Parker, R., Watts, J. (Eds.), Proceedings of INTERCOH-1994: Cohesive Sediments, John Wiley \& Son, Chichester, England, pp. 87-104.

Gratiot, N. and Manning, A.J., 2007. A laboratory study of dilute suspension mud floc characteristics in an oscillatory diffusive turbulent flow. Journal of Coastal Research, SI50, pp. 1142-1146.

Healy, T.R., Wang, Y. and Healy, J.-A. (Eds.), 2002. Muddy Coasts of the World: Processes, Deposits and Function. Elsevier, Amsterdam, The Netherlands.

Hinze, J.O., 1975. Turbulence, second ed. McGraw-Hill, NY.

Krishnappan, B.G., 1991. Modelling of cohesive sediment transport. Proceedings of International Symposium 'The Transport of Suspended Sediments and its Mathematical Modelling', IAHR, Florence, Italy.

Krone, R.B., 1963. A study of rheological properties of estuarial sediments. Report No. 63-68, Hydraulic Engineering Laboratory and Sanitary Engineering Laboratory, University of California, Berkeley.

Lee, B.J., Toorman, E., Molz, F., Wang, J., 2011. A two-class population balance equation yielding bimodal flocculation of marine or estuarine sediments. Water Research 45, 2131-2145.

Lee, B.J., Fettweis, M., Toorman, E., Molz, F.J., 2012. Multimodality of a particle size distribution of cohesive suspended particulate matters in a coastal zone. Journal of Geophysical Research 117 (C03014), doi: 10.1029/2011JC007552.

Manning, A.J., 2004. Observations of the properties of flocculated cohesive sediment in three western European estuaries. In: Ciavola, P., Collins, M.B. (eds), Sediment Transport in European Estuaries, Journal of Coastal Research, vol. SI 41, pp. 90-104.

Manning, A.J., Dyer, K.R., 2002. The use of optics for the in-situ determination of flocculated mud characteristics. Journal of Optics A: Pure and Applied Optics, Institute of Physics Publication, 4, S71-S81.

Manning, A.J., Dyer, K.R., Lafite, R., Mikeš, D., 2004. Flocculation measured by video based instruments in the Gironde estuary during the European Commission SWAMIEE Project. In: Ciavola, P., Collins, M.B. (Eds.), Sediment Transport in European Estuaries, Journal of Coastal Research, vol. SI 41, pp. 58-69.

Manning, A.J., Dyer, K.R., 2007. Mass settling flux of fine sediments in Northern European estuaries: measurements and predictions. Marine Geology 245, 107-122.

Manning, A.J., Martens, C., de Mulder, T., Vanlede, J., Winterwerp, J.C., Ganderton, P. and Graham, G.W., 2007. Mud floc observations in the turbidity maximum zone of the Scheldt Estuary during neap tides. Journal of Coastal Research, SI50, 832-836.

Manning, A.J., van Kessel, T., Melotte, J., Sas, M., Winterwerp, J.C. and Pidduck, E.L., 2011. On the consequence of a new tidal dock on the sedimentation regime in the Antwerpen area of the Lower Sea Scheldt. Continental Shelf Research, doi:10.1016/j.csr.2010.10.008.

Nezu, I. and Nakagawa, H., 1993.Turbulence in Open Channel Flows. International Association for Hydraulic Research, Monograph Series, Balkema, Rotterdam.

Pejrup, M., Mikkelsen, O.A., 2010. Factors controlling the field settling velocity of cohesive sediment in estuaries. Estuarine, Coastal and Shelf Science 87, 177-185. 
Smoluchowski, M., 1917. Versuch einer mathematischen Theorie der Koagulationskinetic kolloider Lösungen. Zeitschrift für Physikalische Chemie, Leipzig 92, 129-168 (in German).

Soulsby, R.L., Manning, A.J., 2012. Cohesive sediment settling flux: settling velocity of flocculated mud. Technical Note DDY0409-01, HR Wallingford, Wallingford, UK.

Spearman J., Manning A.J. and Whitehouse R.J.S., 2011. The settling dynamics of flocculating mud:sand mixtures: Part 2 - Numerical modelling. Proceedings of 10th International Conference on Cohesive Sediment Transport, Rio de Janeiro, Brazil, May 2009. Ocean Dynamics 61 (2-3), 351-370.

Spencer, K.L., Manning, A.J., Droppo, I.G., Leppard, G.G. and Benson, T. 2010. Dynamic interactions between cohesive sediment tracers and natural mud. Journal of Soils and Sediments, Volume 10 (7), doi:10.1007/s11368-010-0291-6.

Van Leussen, W., 1988. Aggregation of particles, settling velocity of mud flocs: a review. In: Dronkers, J., van Leussen, W. (Eds.), 'Physical Processes in Estuaries'. Springer-Verlag, Berlin, pp. 347-403.

Van Leussen, W., 1994. Estuarine macroflocs and their role in fine-grained sediment transport. Ph.D. Thesis, University of Utrecht, The Netherlands, 488p.

Verney, R., Lafite, R., Brun-Cottan, J.C., Le Hir, P., 2010. Behaviour of a floc population during a tidal cycle: laboratory experiments and numerical modelling. Continental Shelf Research 31(10 supplement), S64-S83.

Whitehouse, R.J.S., Soulsby, R.L., Roberts, W., Mitchener, H.J., 2000. Dynamics of Estuarine Muds. Thomas Telford, London,UK.

Winterwerp, H., 1999. On the dynamics of high-concentrated mud suspensions. Communications on Hydraulic and Geotechnical Engineering Report No. 99-3, Delft University of Technology, The Netherlands.

Winterwerp, J.C., Manning, A.J., Martens, C., de Mulder, T., Vanlede, J., 2006. A heuristic formula for turbulence-induced flocculation of cohesive sediment. Estuarine, Coastal and Shelf Science 68, 195-207.

\section{Figure captions}

Figure 1 Dependence of effective excess density on floc size with curves fitted separately for microflocs and Macroflocs. The $20 \mu \mathrm{m}$ limit of resolution of INSSEV, and the $160 \mu \mathrm{m}$ dividing line between microflocs and Macroflocs are shown

Figure 2 Proportion $r$ of SPM attributable to Macroflocs, MD07 data (symbols) and fitted line (Eq 12): (a) subdivided by shear-stress (tau, N. $\mathrm{m}^{-2}$ ), (b) subdivided by estuary

Figure 3 Comparison of predicted settling velocities with observed values for MD07 data for (a) Macroflocs (Eq 10), (b) microflocs (Eq 11)

Figure $4 \quad$ Comparison of predicted (Eq 14) and observed mass settling flux (MSF) for (a) 113 MD07 data for Tamar and Gironde, (b) 105 independent data for Scheldt and 2003 Tamar. The original calibration coefficients were used in both cases.

Figure 5 Test of performance of depth-dependence of predictions of MSF (Eq 14) against 113 observed values in Tamar and Gironde. Open symbols: individual data; filled symbols: median values in each band of relative depth $z / h$ of widths 0.1

Figure. 6 Comparison of predicted (Eq 14) and observed mass settling flux through tidal cycles in the estuaries of (a) Tamar (2003 data), (b) Scheldt. The original calibration coefficients were used in both cases. 
Table 1: Root-mean-square residual errors of variables $=\left[113^{-1} \Sigma(\text { obs }- \text { pred })^{2}\right]^{1 / 2}$

\begin{tabular}{|l|r|r|}
\hline Variable & Equation & RMS error of fit \\
\hline$W_{\mathrm{sM}}$ & 10 & $0.488 \mathrm{~mm} \cdot \mathrm{s}^{-1}$ \\
\hline $\mathrm{W}_{\mathrm{s \mu}}$ & 11 & $0.171 \mathrm{~mm} \cdot \mathrm{s}^{-1}$ \\
\hline $\mathrm{r}$ & 12 & 0.132 \\
\hline $\mathrm{W}_{\mathrm{s}, \mathrm{av}}$ & 13 & $0.404 \mathrm{~mm} \cdot \mathrm{s}^{-1}$ \\
\hline $\mathrm{MSF}$ & 14 & $0.00124 \mathrm{~kg} \cdot \mathrm{m}^{-2} \cdot \mathrm{s}^{-1}$ \\
\hline
\end{tabular}

Table 2: Standard deviations of absolute $\left(\sigma_{\text {abs }}\right)$ and relative $\left(\sigma_{\text {rel }}\right)$ differences between predicted and measured settling velocities presented by Winterwerp et al. (2006), compared with the SM12 method.

\begin{tabular}{|c|c|c|c|c|c|c|c|c|}
\hline $\begin{array}{l}\text { Conc. } \\
\text { range } \\
\mathrm{kg} \cdot \mathrm{m}^{-3}\end{array}$ & $<0.1$ & $0.1-0.2$ & $0.2-0.5$ & $0.5-1.0$ & $1.0-2.0$ & $2.0-4.0$ & $4.0-9.0$ & All data \\
\hline \multicolumn{9}{|c|}{ Winterwerp et al (2006) method for Macroflocs for Tamar } \\
\hline$\sigma_{\mathrm{abs}} \mathrm{mm} / \mathrm{s}$ & 0.23 & 0.45 & 0.72 & 0.80 & 1.20 & 1.11 & 0.64 & 0.69 \\
\hline$\sigma_{\text {rel }}(\%)$ & 17 & 31 & 39 & 35 & 52 & 44 & 15 & 31 \\
\hline \multicolumn{9}{|c|}{ SM12 method for Macroflocs for Tamar \& Gironde } \\
\hline$\sigma_{a b s} \mathrm{~mm} / \mathrm{s}$ & 0.40 & 0.47 & 0.43 & 0.33 & 0.65 & 0.68 & 0.74 & 0.49 \\
\hline$\sigma_{\text {rel }}(\%)$ & 27 & 29 & 23 & 12 & 29 & 28 & 14 & 25 \\
\hline \multicolumn{9}{|c|}{ SM12 method for $\mathrm{w}_{\mathrm{s}, \mathrm{av}}$ for Tamar \& Gironde } \\
\hline$\sigma_{\mathrm{abs}} \mathrm{mm} / \mathrm{s}$ & 0.25 & 0.28 & 0.32 & 0.34 & 0.63 & 0.63 & 0.74 & 0.40 \\
\hline$\sigma_{\text {rel }}(\%)$ & 29 & 27 & 24 & 18 & 35 & 28 & 15 & 27 \\
\hline \multicolumn{9}{|c|}{ SM12 method for $\mathrm{W}_{\mathrm{s}, \mathrm{av}}$ for Scheldt \& 2003 Tamar } \\
\hline$\sigma_{a b s} \mathrm{~mm} / \mathrm{s}$ & 0.51 & 0.46 & 0.55 & 0.84 & 0.98 & 0.58 & 0.34 & 0.59 \\
\hline$\sigma_{\text {rel }}(\%)$ & 90 & 57 & 31 & 88 & 92 & 27 & 8 & 77 \\
\hline
\end{tabular}

Table 3: Summary of statistical tests of accuracy of six methods for predicting MSF,M1: Manning empirical flocculation model; M2: constant $\mathrm{W}_{\mathrm{s}}=0.5 \mathrm{~mm} . \mathrm{s}^{-1} ; \mathrm{M} 3$ : constant $\mathrm{W}_{\mathrm{s}}=5.0 \mathrm{~mm} \cdot \mathrm{s}^{-1} ; \mathrm{M} 4$ : fitted power-law $\mathrm{W}_{\text {smean }}$ versus SPM; M5: Van Leussen (1994) approach; SM12: Eqs (8-14). The statistics for methods M1 - M5 and SM12-Cal are based on the same 113 samples (those with depth measurements), and differ slightly from the figures in Table 2 of MD07 which were based on 157 samples. The statistics for SM12-Ind are for the 105 independent test data from Tamar (2003) and Scheldt (2005)

\begin{tabular}{|l|r|r|r|r|r|r|r|}
\hline Statistical test & M1 & M2 & M3 & M4 & M5 & SM12-Cal & $\begin{array}{r}\text { SM12- } \\
\text { Ind }\end{array}$ \\
\hline Mean error (\%) & -0.8 & -66.2 & 238.3 & -22.9 & 14.9 & 4.2 & 48.8 \\
\hline Std. deviation (\%) & 9.5 & 17.8 & 177.6 & 24.2 & 33.8 & 26.1 & 60.1 \\
\hline Total Cumulative & 0.959 & 0.136 & 1.36 & 0.622 & 0.628 & 0.987 & 1.21 \\
\hline MSF (pred/obs) & & & & & & & \\
\hline
\end{tabular}




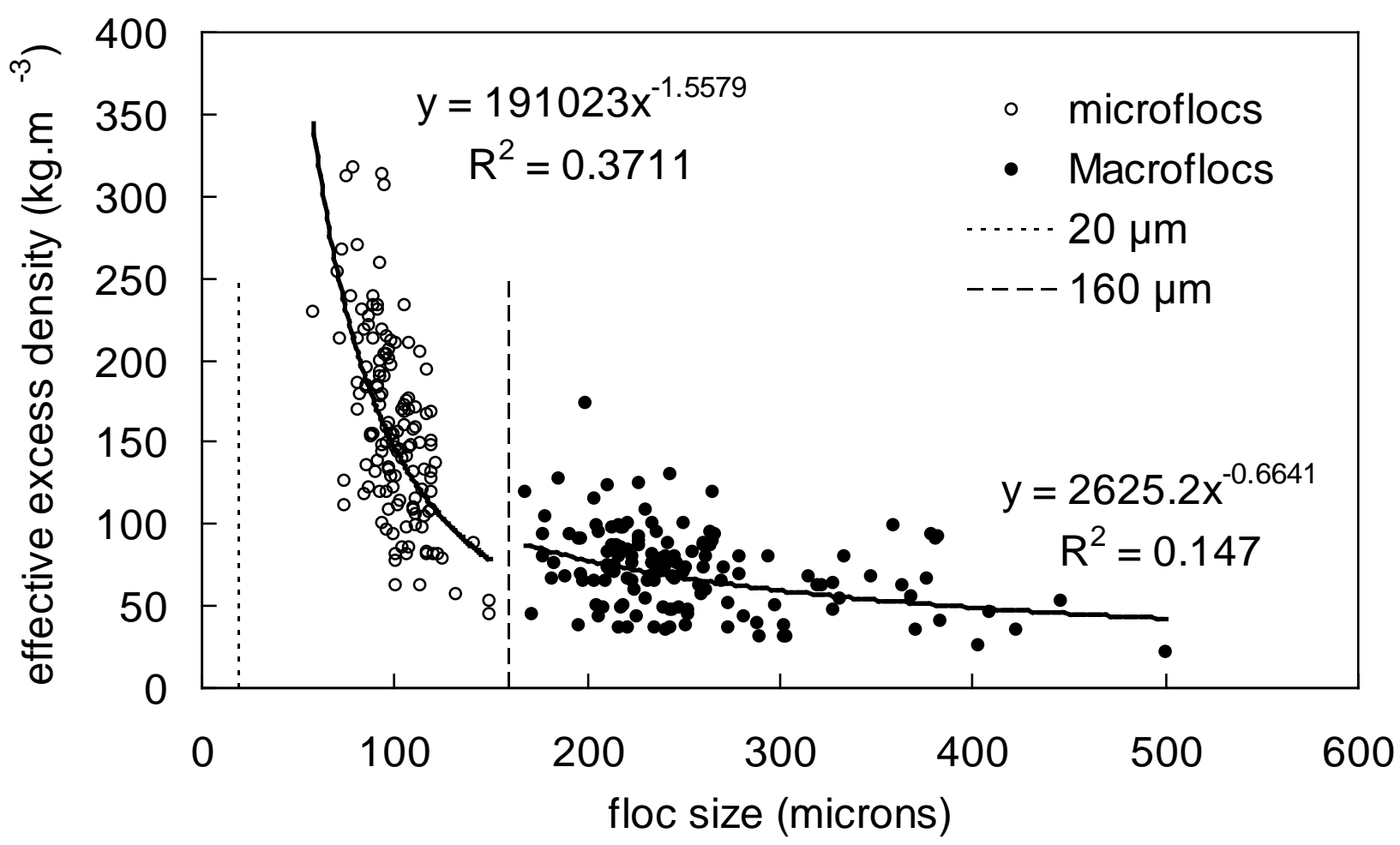

Figure 1: Dependence of effective excess density on floc size with curves fitted separately for microflocs and Macroflocs. The $20 \mu \mathrm{m}$ limit of resolution of INSSEV, and the $160 \mu \mathrm{m}$ dividing line between microflocs and Macroflocs are shown 

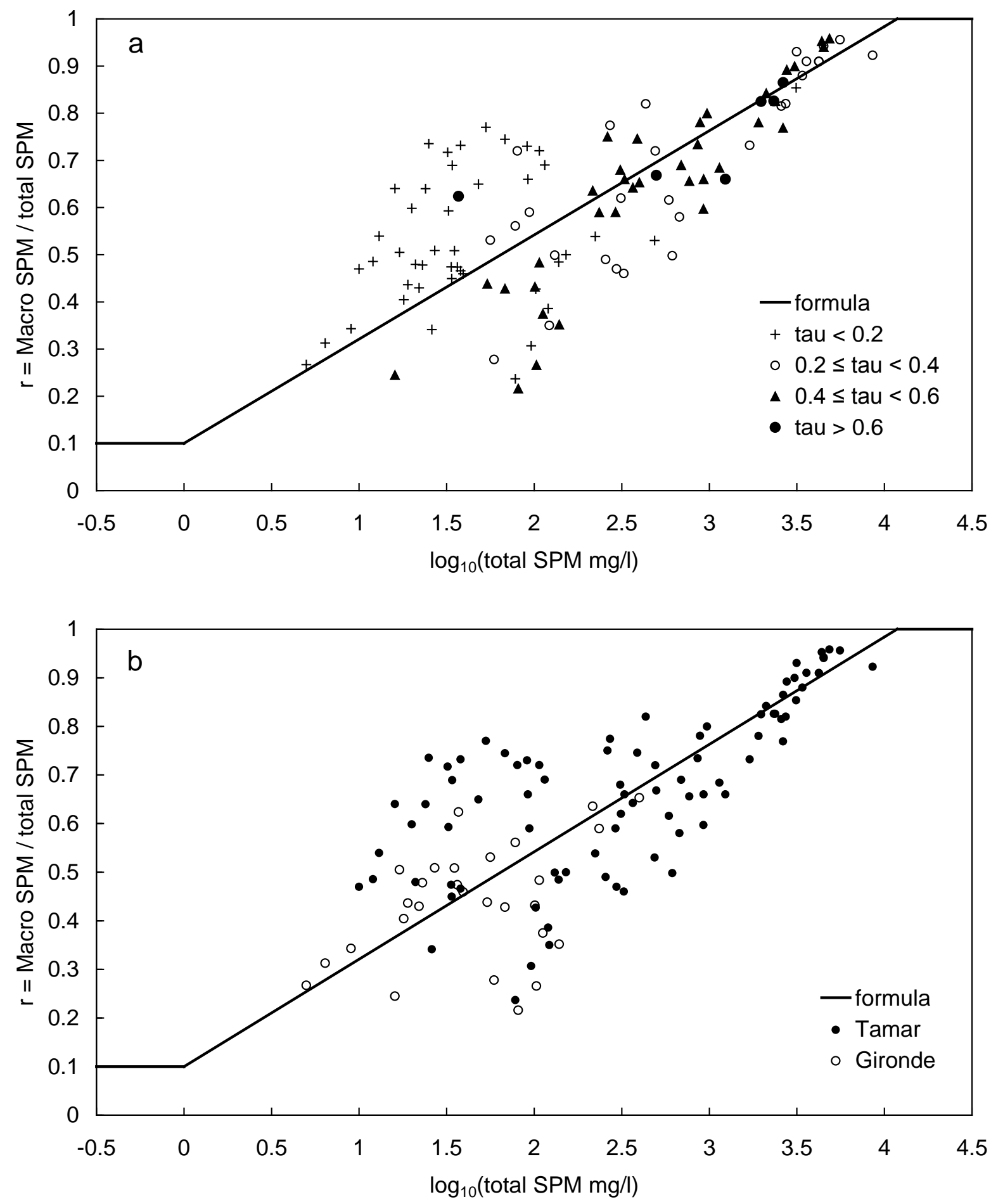

Figure 2: Proportion r of SPM attributable to Macroflocs, MD07 data (symbols) and fitted line (Eq 12): (a) subdivided by shear-stress (tau, N. $\mathrm{m}^{-2}$ ), (b) subdivided by estuary 

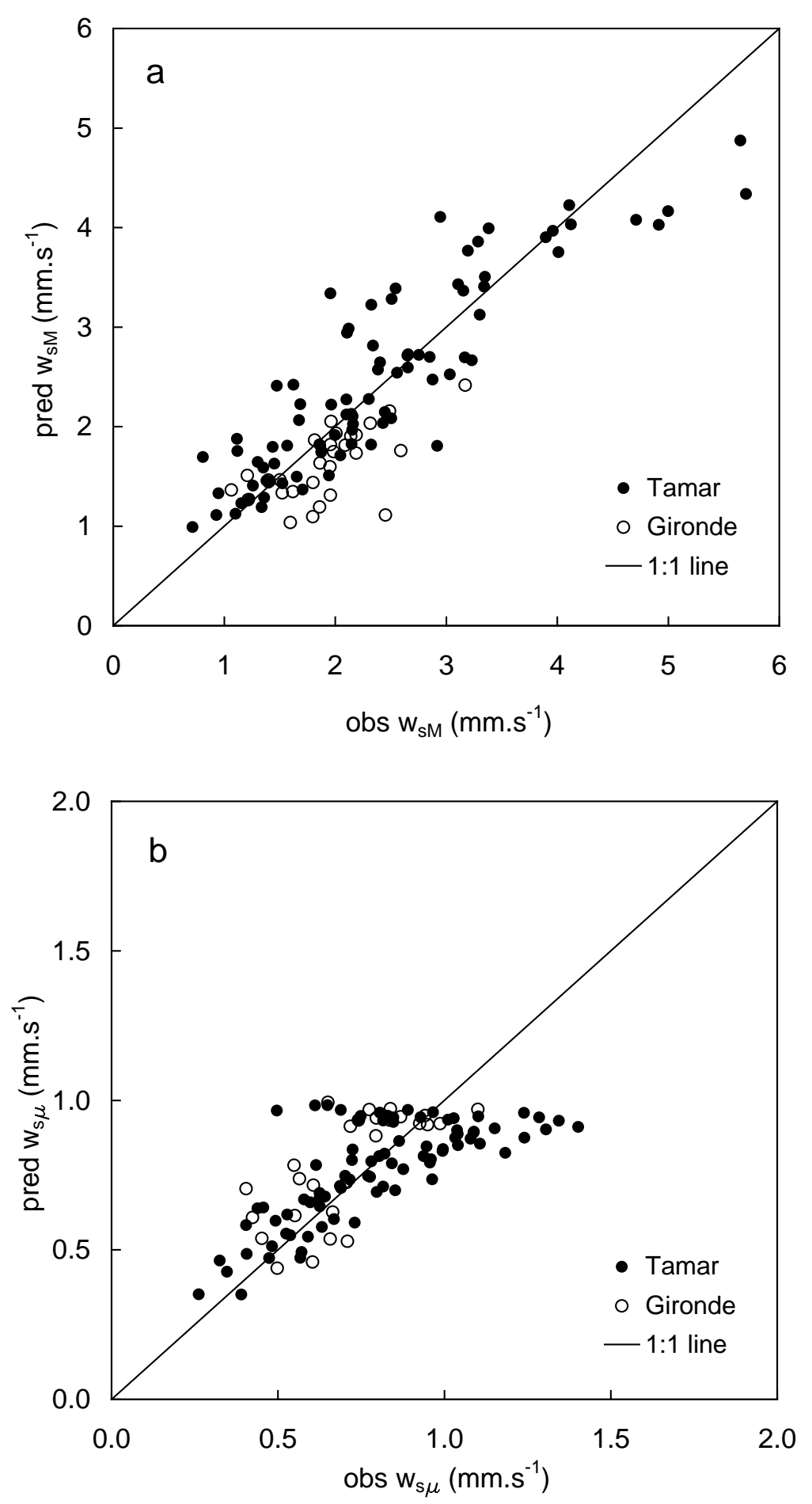

Figure 3: Comparison of predicted settling velocities with observed values for MD07 data for (a) Macroflocs (Eq 10), (b) microflocs (Eq 11) 

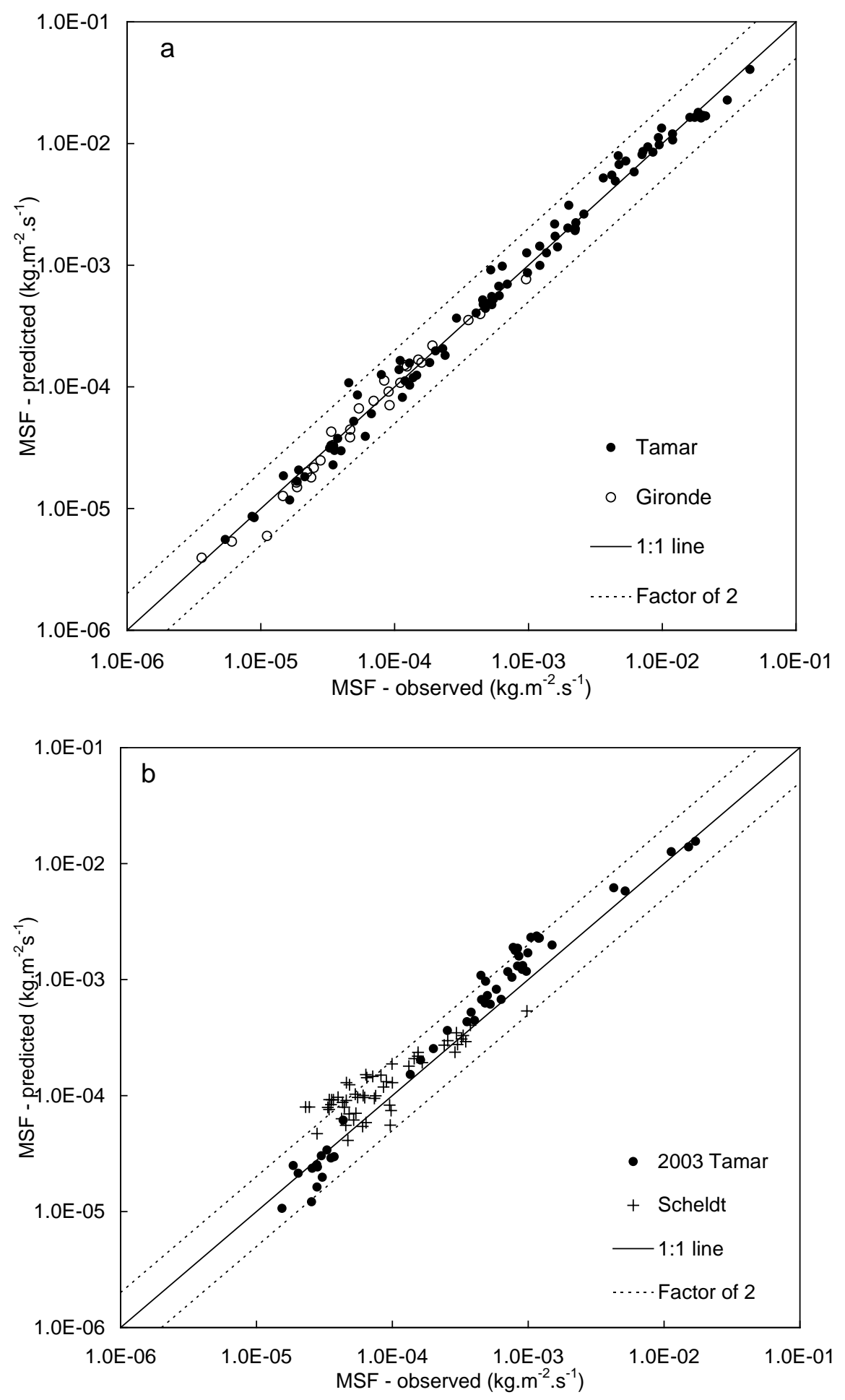

Figure 4: Comparison of predicted (Eq 14) and observed mass settling flux (MSF) for (a) 113 MD07 data for Tamar and Gironde, (b) 105 independent data for Scheldt and 2003 Tamar. The original calibration coefficients were used in both cases. 


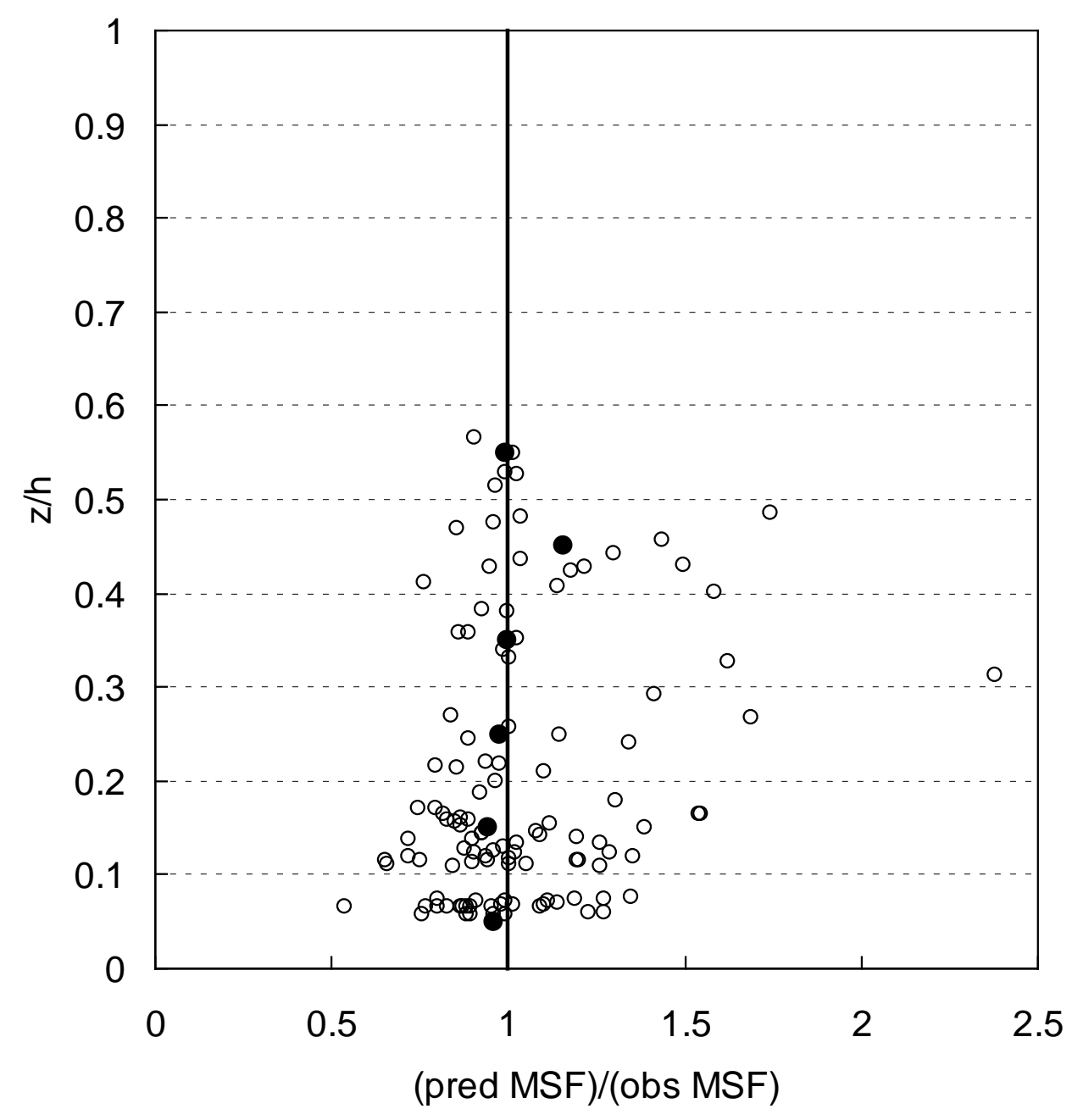

Figure 5: Test of performance of depth-dependence of predictions of MSF (Eq 14) against 113 observed values in Tamar and Gironde. Open symbols: individual data; filled symbols: median values in each band of relative depth $\mathrm{z} / \mathrm{h}$ of widths 0.1 

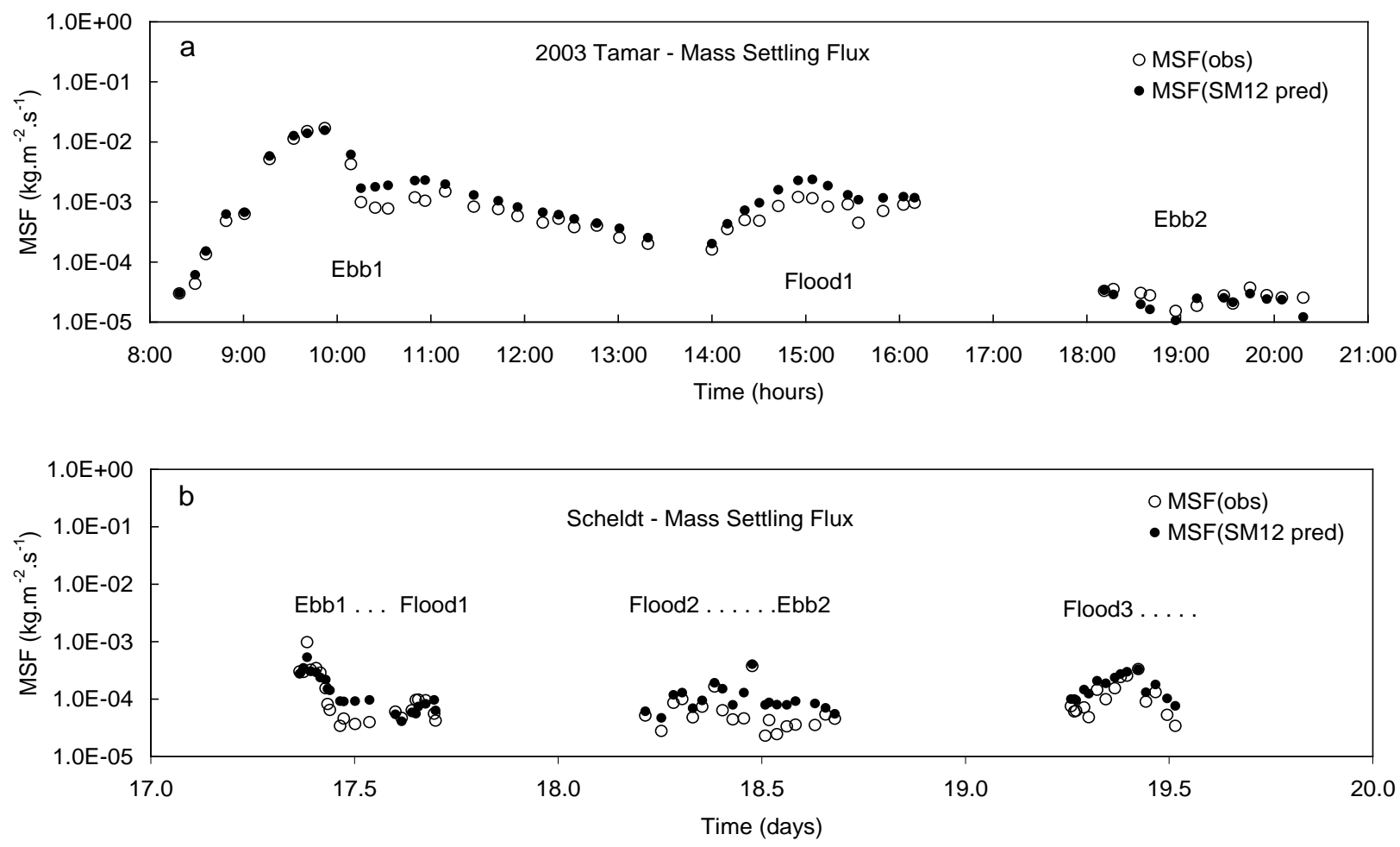

Figure 6: Comparison of predicted (Eq 14) and observed mass settling flux through tidal cycles in the estuaries of (a) Tamar (2003 data), (b) Scheldt. The original calibration coefficients were used in both cases. 